\title{
Pengembangan Game Edukasi Untuk Anak Usia Dini Berbasis Mobile Menggunakan Construct 2
}

\author{
Sri Mulyatun ${ }^{[1]}$, Hendrik ${ }^{[2]}$, Mei Maemunah ${ }^{[3]}$, Sri Ngudi Wahyuni \\ Fakultas Ilmu Komputer, Universitas Amikom Yogyakarta \\ Jl. Ringroad Utara, Depok, Condongcatur, Sleman, Yogyakarta \\ sri.m@amikom.ac.id ${ }^{[1]}$ Cohendri10@gmail.com ${ }^{[2]}$ mei.m@amikom.ac.id ${ }^{13]}$, yuni@amikom.ac.id
}

\begin{abstract}
The current Covid-19 pandemic has changed cultures around the world, including learning culture. Because Covid-19 has become a pandemic, learning from home. Android is the easiest-to-use communication and study aid, and nearly everyone has one. The frequency of Android makes gameplay the most popular, so it dominates children, including early childhood. This study aims to build educational games for children of early education based on mobile, using construct 2 . This game's test results state that $70 \%$ of potential users say that this game is excellent and safe to use. In terms of appearance, color, and user interface
\end{abstract}

Keywords-Education game, childhood, mobile-based

Abstrak-Perkembangan Covid-19 saat ini telah merubah budaya di seluruh dunia, termasuk budaya dalam belajar. Dikarenakan Covid-19 telah menjadi pandemi, maka belajar harus dilaksanakan dari rumah (BDR). Hal ini menyebabkan keterbutuhan teknologi menjadi utama, terutama kepemilikan gadget. Gadget merupakan media komunikasi dan pembelajaran yang paling mudah digunakan dan hampir seluruh orang memilikinya. Frekuensi penggunaan smartphone menyebabkan penggunaan game telah mendominasi anak-anak, termasuk anak usia dini. Berdasarkan hal tersebut maka tujuan penelitian ini adalah membangun game edukasi untuk anakanak usia pendidikan dini berbasis mobile, dengan menggunakan construc 2. Adapun hasil pengujian game ini menyatakan bahwa $70 \%$ calon pengguna menyatakan bahwa game ini baik dan aman digunakan. Dari sisi tampilan, warna dan user interfacenya.

Kata Kunci-Game edukasi, anak usia dini, mobile base

\section{INTRODUCTION}

Perkembangan Covid-19 saat ini telah merubah budaya di seluruh dunia, termasuk budaya dalam belajar. Dikarenakan Covid-19 telah menjadi pandemi, maka belajar harus dilaksanakan dari rumah (BDR). Hal ini menyebabkan keterbutuhan teknologi menjadi utama, terutama kepemilikan gadget. Gadget merupakan media komunikasi dan pembelajaran yang paling mudah digunakan dan hampir seluruh orang memilikinya. Tetapi hingga saat ini ketergantungan terhadap gadget tidak hanya sebagai alat komukasi dan pembelajaran, tetapi sebagai alat bermain yang sangat diminati semua orang, baik tua maupun muda. Sehingga peminat game online semakin hari semakin meningkat [1]. Pada tahun 2020 peminat game berbasis mobile meningkat hingga $57 \%$ dibanding dari tahun sebelumnya. Agar anak-anak aman dalam bermain game maka perlu dibangun suatu game yang mampu mengedukasi. Salah satu game yang dapat dijadikan pembelajaran anak-anak adalah game berbasis edukasi. Game Edukasi adalah permainan yang dirancang untuk merasang daya pikir termasuk konsentrasi dan memecahkan masalah. Adapun statistik peningkatan penggunaan game di Indonesia ditunjukkan pada Gambar 1.

\section{2-2021 GLOBAL GAMES MARKET}

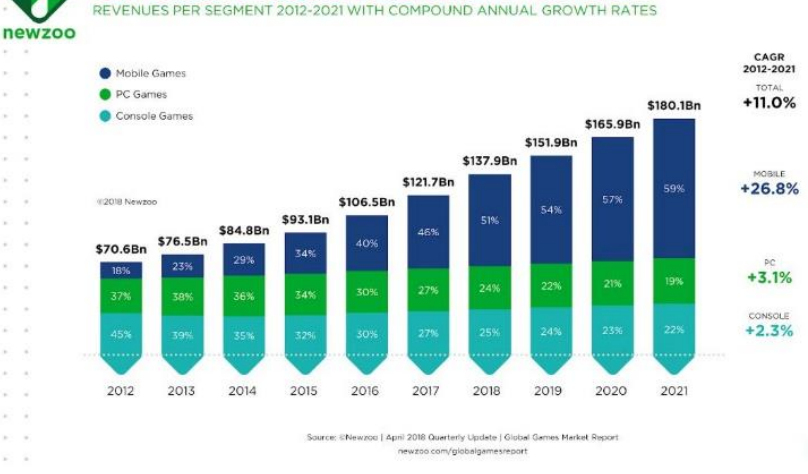

Gambar 1. Grafik peningkatan penggunaan game dalam 10 tahun terakhir.

Gambar 1. Menunjukkan kenaikan penggunaan game secara signifikan mengalami peningkatan pesat. Terutama pada masa pandemi COVID-19. Berdasarkan uraian diatas maka tujuan dari penelitian ini adalah, membangun game edukasi untuk anak-anak usia pendidikan dini, agar lebih aman bermain game.

Game atau permainan adalah sesuatu yang dapat dimainkan dengan aturan tertentu sehingga ada yang menang dan ada yang kalah, biasanya dalam konteks tidak serius dengan tujuan refreshing. Bermain game sudah dapat dikatakan sebagai life style masyarakat dimasa kini. Dimulai 
dari usia anak-anak hingga orang dewasa pun menyukain video game. itu semua dikarenakan bermain video game adalah hal yang menyenangkan. Game bertujuan untuk menghibur, biasanya game banyak disukai oleh anak-anak hingga orang dewasa. Games sebernarnya penting untuk perkembangan otak, untuk meningkatkan kosentrasi dan melatih untuk memecahkan masalah dengan tepat dan cepat karena dalam game terdapat berbagai konflik atau masalah yang menuntut kita untuk menyelesaikannya dengan cepat dan tepat. Game saat ini bukan hanya sekedar permainan untuk mengisi waktu luang dan hobi saja. Namun bermain game untuk meningkatkan kreatifitas dan intektual bagi pemainnya. Pada saat bermain game juga secara nyata mempertajam daya analisis para penggunanya untuk mengolah informasi dan mengambil keputusan secara tepat. Ada juga pengertian lain bahwa game digunakan sebagai alat pembalajaran, tetapi game juga bisa merugikan apabila kita sudah kecanduan game kita akan lupa waktu dan akan mengganggu kegiatan atau aktifitas yang sedang kita lakukan. Adapun mekanisme penulisan pada penelitian ini adalah metode penelitian yang akan disajikan pada bagian II, analisis hasil disajikan pada bagian III dan kesimpulan disajikan pada bagian IV.

\section{METODE PENELITIAN}

\section{A. Metode penelitian}

Adapun alur penelitian yang digunakan pada penelitian digambarkan pada Gambar 2.

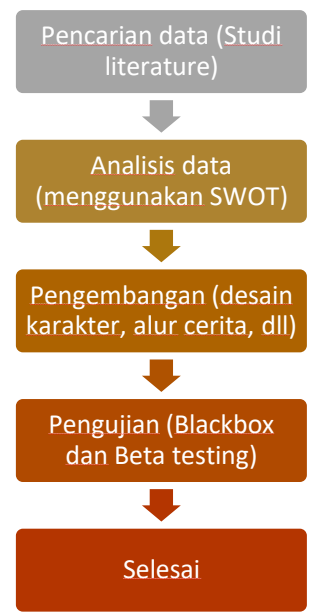

Gambar 2. Metode penelitian

Gambar 2 menjelaskan tahapan penelitian yang akan dejelaskan pada bab-bab selanjutnya.

\section{B. Metode pengumpulan data}

Data penelitian ini diambil dari sumber online yaitu 21 Best Sites To Download Amazing Game Assets For Free Gaming Shift. URL ini digunakan untuk mendapatkan referensi aset-aset pengembangan game, selain mengembangkan aset lain yang sesuai tema game.

\section{Metode analisis data}

Metode analisis data pada penelitian ini menggunakan analisis SWOT yaitu SWOT merupakan akronim dari kata: kekuatan (strengths), kelemahan (weaknesses), peluang (opportunities), dan ancaman (threats). Pendekatan ini digunakan untuk melakukan analisis masalah pada pengembangan game ini. Adapun analisis data dijelaskan pada Tabel 1.

\section{TABEL 1. TABEL HASIL ANALISIS DATA MENGGUNAKAN SWOT}

\begin{tabular}{|c|c|c|}
\hline $\begin{array}{c}\text { Faktor Internal } \\
\text { Eksternal }\end{array}$ & Kekuatan (S) & Kelemahan (W) \\
\hline & $\begin{array}{l}\text { - Game mudah dimainkan } \\
\text { oleh anak-anak } \\
\text { - Game bersifat offline } \\
\text { sehingga tidak banyak } \\
\text { menggunakan quota } \\
\text { - Game mudah diakses } \\
\text { menggunakan } \\
\text { smartphone } \\
\text { - Game membantu anak } \\
\text { untuk melatih } \\
\text { konsentrasi anak } \\
\text { - Game melatih ang an } \\
\text { untuk menghitung } \\
\text { dengan cara menangkap } \\
\text { koin. bermain } \\
\text { - Belajar sambil berik, } \\
\text { game lebih menarih, dan } \\
\text { karena audio debih } \\
\text { visualnya a } \\
\text { berwarna. }\end{array}$ & $\begin{array}{l}\text { - Smartphone } \\
\text { menjadi lambat } \\
\text { aksesnya karena } \\
\text { sering digunakan } \\
\text { bermain game. } \\
\text { - Memori } \\
\text { smartphone } \\
\text { menjadi penuh } \\
\text { karena harus } \\
\text { mendownload } \\
\text { game. anak } \\
\text { - Gerak terbatas } \\
\text { menjadi suka } \\
\text { karena lebih } \\
\text { main game. } \\
\text { - Belum mampu } \\
\text { membangun } \\
\text { karakter yang } \\
\text { menantang } \\
\text { sehingga masih } \\
\text { menggunakan } \\
\text { karakter seadanya. } \\
\text { - Belum mampu } \\
\text { memvisualisasikan } \\
\text { game dengan } \\
\text { maksimal. }\end{array}$ \\
\hline Peluang (O) & $\begin{array}{c}\text { (Strategi S-O) (Strategi } \\
\text { W-O) }\end{array}$ & $\begin{array}{c}\text { (Strategi } \quad \text { S-O) } \\
(\text { Strategi W-O) }\end{array}$ \\
\hline $\begin{array}{l}\text { - } \text { Informasi } \\
\text { karakter dan } \\
\text { gambar banyak } \\
\text { tersedia dan } \\
\text { didapatkan } \\
\text { dengan open } \\
\text { source } \\
\text { - Anak-anak } \\
\text { menyukai game } \\
\text { - Game } \\
\text { digunakan } \\
\text { sebagai sarana } \\
\text { belajar } \\
\text { menghitung. } \\
\text { - Kemudahan } \\
\text { dalam } \\
\text { mengakses } \\
\text { game }\end{array}$ & 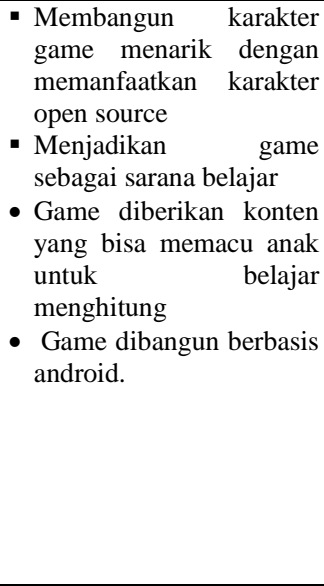 & $\begin{array}{l}\text { - Memanfaatkan } \\
\text { gambar-gambar } \\
\text { menarik sebagai } \\
\text { karakter game. } \\
\text { - Game dibangun } \\
\text { dengan interaktif } \\
\text { dan mudah } \\
\text { dimainkan oleh } \\
\text { anak-anak } \\
\text { - Game didownload } \\
\text { melalui playstore }\end{array}$ \\
\hline Ancaman (T) & Strategi (S-T) & Strategi (W-T) \\
\hline $\begin{array}{l}\text { Anak-anak } \\
\text { malas belajar }\end{array}$ & $\begin{array}{l}\text { - } \text { Belajar dengan } \\
\text { menggunakan media } \\
\text { game }\end{array}$ & $\begin{array}{l}\text { - Membangun game } \\
\text { yang aman untuk } \\
\text { anak-anak }\end{array}$ \\
\hline
\end{tabular}

Adapun metode pengujian game menggunakan pengujian beta Yaitu pengujian kepada calon pengguna dengan menarik opini ata pendapat calon pengguna tentang game ini.

\section{Metode pengujian game}

Pada tahapan pengujian game akan menggunakan pengujian Beta (Beta testing) yaitu pengujian menggunakan metode skala linkert. Pengujian ini digunakan untuk mengukur opini 
calon pengguna, berdasarkan skala tertentu [6]. Pengujian ini bertujuan untuk mengetahui apakah game yang dibangun untuk anak-anak usia 2-4 tahun ini, cukup aman atau tidak. Skala pengukuran ditampilkan pada Tabel 2.

TABEL 2. SKALA PENGUJIAN

\begin{tabular}{|c|l|}
\hline Skala & \multicolumn{1}{|c|}{ Keterangan } \\
\hline 1 & Sangat tidak setuju \\
\hline 2 & Tidak setuju \\
\hline 3 & Setuju \\
\hline 4 & Sangat setuju \\
\hline
\end{tabular}

Tabel 2 menjelaskan nilai atau skala pengujian. Adapun perhitungan kuesioner diperoleh dengan rumus sebagai berikut:

$$
\begin{aligned}
& Y=X \text { Skor Ideal } \times 100 \% \\
& \mathrm{X}=\Sigma(\mathrm{N} \times \mathrm{R})
\end{aligned}
$$

Skor Ideal $=$ nilai linkert tertinggi $\times$ jumlah responden

Keterangan:

$\mathrm{Y}=$ nilai prosentase yang dicari

$\mathrm{X}=$ jumlah dari hasil perkalian nilai setiap jawaban dengan responden

$\mathrm{N}=$ nilai dari setiap jawaban

$\mathrm{R}=$ jumlah responden

Adapun uji dalam kuesioner tertera pada Tabel 4.

TABEL 3. DAFTAR PERTANYAAN PENGUJIAN GAME EDUKASI

\begin{tabular}{|c|l|}
\hline No & \multicolumn{1}{|c|}{ Pertanyaan } \\
\hline 1 & $\begin{array}{l}\text { Kesesuaian penggunaan warna dan desain latar belakang } \\
\text { (background) }\end{array}$ \\
\hline 2 & Kesesuaian warna tulisan dengan latar belakang (background) \\
\hline 3 & Game edukasi user friendly \\
\hline 4 & Ketetapan fungsi tombol dengan tujuan menu yang diinginkan \\
\hline 5 & Kesesuaian tampilan animasi \\
\hline 6 & $\begin{array}{l}\text { Kesesuaian ilustrasi musik dalam mendukung education game } \\
\text { untuk belajar berhitung }\end{array}$ \\
\hline 7 & Ketepatan pemilihan warna tulisan \\
\hline 8 & Kesesuaian ukuran tombol \\
\hline 9 & Kesesuaian warna tombol \\
\hline 10 & Kesesuaian bentuk tombol \\
\hline 11 & Kenyamanan menggunakan aplikasi secara keseluruhan \\
\hline
\end{tabular}

Tabel 3 adalah daftar pertanyaan yang digunakan untuk mengambil data lapangan sebagai data pengujian. Kuesioner ini telah diisi oleh 50 responden dari orang tua yang memiliki anak usia dini.

III. ANALISIS DAN PEMBAHASAN

Permainan Jumping Game ini dibuat menggunakan Construct
Game Engine. Game ini memiliki jalan cerita aksi pengumpulan koin atau gold, sekaligus menghindari bomb, besi baja yg jatuh, dan awan yang bergerak. Game yang dibangun ini termasuk dalam Enless Jumping, yaitu pengguna adalah actor utama dalam game. Permainan ini ditujukan untuk anak-anak usia 2-4 tahun sebagai media belajar dan melatih konsentrasi. Mendapatkan software Construct, bisa didownload master program dari situs resmi https://www.scirra.com/construct2/. Adapun flowchart jalannya game dan back sound disajikan pada Gambar 3 dan Gambar 4. Flowchart pada Gambar 3 menjelaskan bahwa game memiliki dua obstacle atau rintangan, yaitu berupa koin emas dan bom. Jika keduanya terlewati makan pemain game ini bisa meneruskan ke level selanjutnya. Flowchart ini berjalan beruang sehingga pemain akan selesai jika tidak bisa melewati rintangan atau obstacle. Adapun Gambar 4 menjelaskan tentang flowchart bascksound atau pemberian suara pada game.

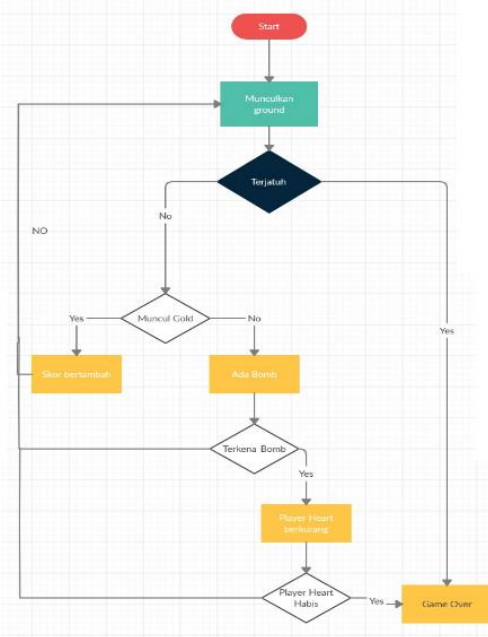

Gambar 3. Flowchart jalannya Game

Gambar 3 merupakan alur atau algoritma jalannya game. Dimulai dengan level pertama dan rintangan berupa bom. Selanjutnya pemain akan naik level jika mampu melewati rintangan atau halangan berupa Bom.

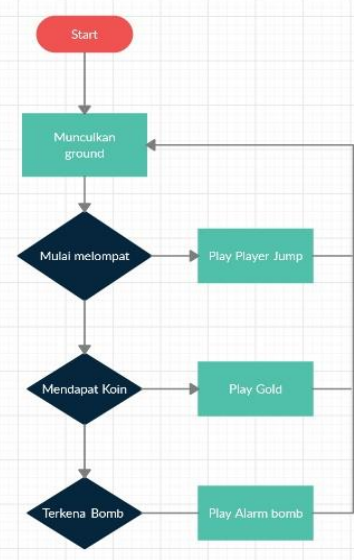

Gambar 4. Flowchart backsound

Gambar 4. Merupakan flowchat pemberian suara. Saat pemain 
terkena bom maka akan ditambahkan suara alarm dan saat pengguna melakukan lompatan atau mendapat koin, akan ditambahkan suara yang berbeda dengan sebelumnya.

\section{A. Worksheet Construct}

Construct merupakan salah satu game enggine berbasis 2 dimensi. Untuk memulai sebuah project contruct dilakukan dengan cara klik menu file $\rightarrow$ New seperti tampak pada gambar dibawah ini.

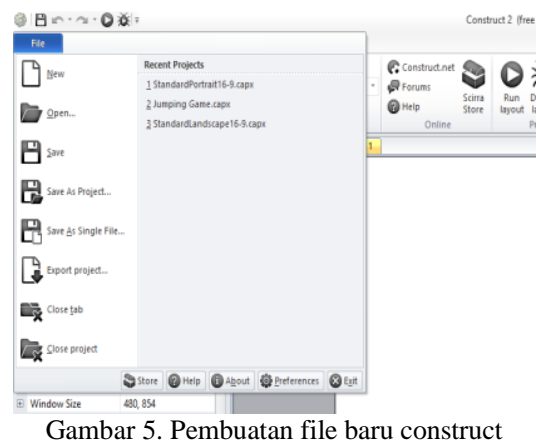

Kemudian muncul jendela template yang berfungsi mengatur ukuran windows size dan layout size. Disini penulis memilih ukuran 16:9 dengan tampilan potrait, karena ukuran ini yang pas untuk tampilan ponsel seperti tersaji pada Gambar 6.

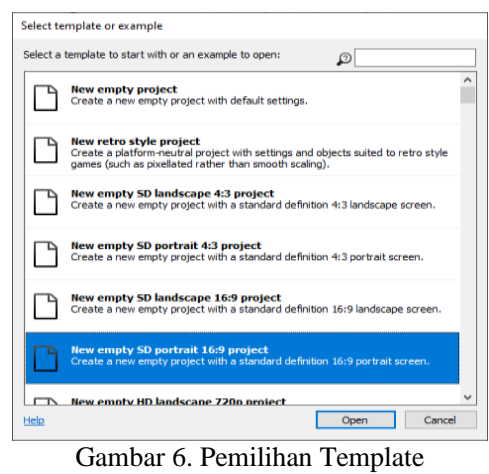

Gambar 6 adalah tampilan worksheet, yang digunakan untuk . Worksheet disini berfungsi sebagai dashboard kerja dalam pembuatan game. Adapun Gambar 7 adalah halaman baru tampilan lembar kerja.

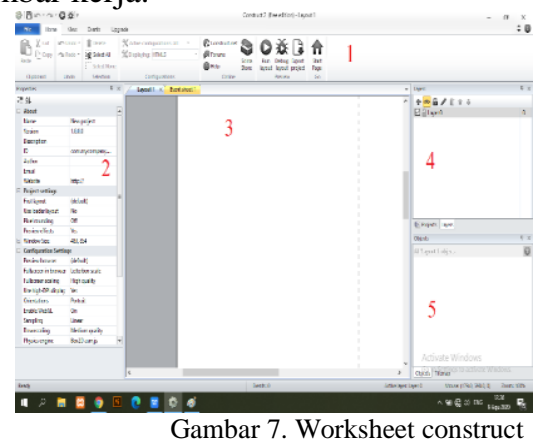

Gambar 7 menjelaskan tentang langkah-langkah dalam memulai pembuatan game menggunakan Contruct 2. Antara lain:
- Panel Toolbar, panel ini berisi berbagai macam alat diantaranya untuk mengedit, menyimpan ,mencoba game yang telah dibuat, juga meng-exportnya.

- Panel property, panel ini berisi keterangan dari obyek yang dipilih, misalnya gambar layer atau file.

- Panel lembar kerja, disini ada bagian layout dimana kita mengatur tata letak. Sedangkan pada bagian event sheet 1 digunakan untuk mangatur fungsi fungsi pada game.

- Panel Layer, berisi jumlah layer dan juga layer mana yang dipilih saat diketjakan.

- Panel Project, panel ini berisi obyek-obyek yang telah dimasukan ke dalam layer.

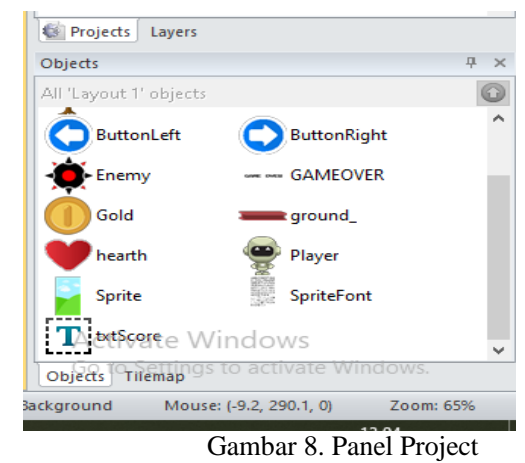

\section{B. Implementasi User Interface}

Implementasi Background Background atau latar belakang game, background ini berfungsi memperindah tampilan pada game. Untuk memasukkan background kita hanya perlu mendrag nya ke layout. Letakkan background ke layer background seperti pada Gambar 9.

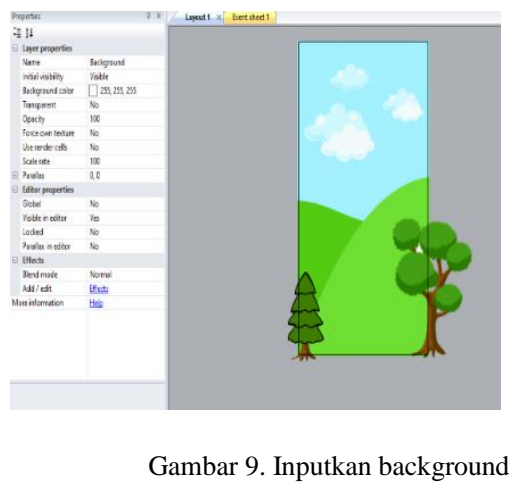

Gambar 9. Adalah tampilan edit paralax pada layer background menbjadi 0,0 agar background tidak bergerak saat game dimainkan.

\section{Ground}

Ground merupakan landasan tokoh utama. Tambahan ground seperti saat menambahakan background letakkan ground pada layer dua atau layer ground seperti tersaji pada Gambar 10. 


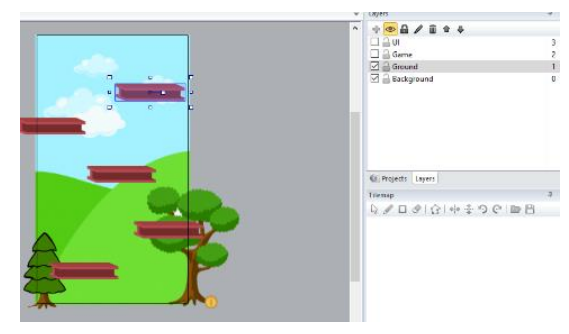

Gambar 10. Inputkan Ground

Tambahkan behavior pada ground, dan penambahan behaviour disajikan pada gambar 11 .

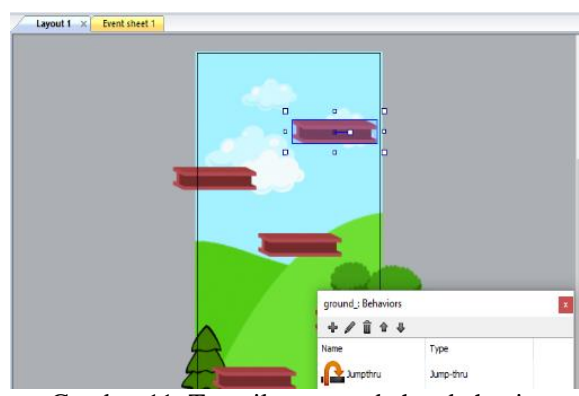

Gambar 11. Tampilan penambahan behavior

\section{Hasil Pengujian}

Berikut adalah hasil pengujian game yang dilakukan oleh 33 responden.

TABEL 4 HASIL PENGUJIAN PERTANYAAN 1

\begin{tabular}{|l|l|l|l|l|}
\hline & Frequency & Percent & $\begin{array}{l}\text { Valid } \\
\text { Percent }\end{array}$ & $\begin{array}{l}\text { Cumulative } \\
\text { Percent }\end{array}$ \\
\hline Tidak Baik & 7 & 20.6 & 21.2 & 21.2 \\
\hline Baik & 20 & 58.8 & 60.6 & 81.8 \\
\hline Sangat Baik & 6 & 17.6 & 18.2 & 100.0 \\
\hline Total & 33 & 97.1 & 100.0 & \\
\hline
\end{tabular}

Tabel 4 diatas menyatakan kesesuaian warna dan desain latar belakang (background) dinyatakan baik. Hal ini ditunjukkan dengan presentase audience sebesar $58.8 \%$.

TABEL 2 HASIL PENGUJIAN PERTANYAAN 2

Tabel 2. menjelaskan kesesuaian warna tombol dinyatakan tidak baik. Hal ini ditunjukkan dengan presentase audience sebesar $57.6 \%$.

TABEL 5 HASIL PENGUJIAN PERTANYAAN 3

\begin{tabular}{|l|l|l|l|l|}
\hline & Frequency & Percent & $\begin{array}{l}\text { Valid } \\
\text { Percent }\end{array}$ & $\begin{array}{l}\text { Cumulative } \\
\text { Percent }\end{array}$ \\
\hline Tidak Baik & 1 & 2.9 & 3.0 & 3.0 \\
\hline Baik & 18 & 52.9 & 54.5 & 57.6 \\
\hline Sangat Baik & 14 & 41.2 & 42.4 & 100.0 \\
\hline Total & 33 & 97.1 & 100.0 & \\
\hline
\end{tabular}

Tabel 3. Menjelaskan data tentang kesesuaian warna tulisan dengan desain latar belakang (background) dinyatakan baik. Hal ini ditunjukkan dengan presentase audience sebesar $54.5 \%$.

TABEL 4. HASIL PENGUJIAN PERTANYAAN 4

\begin{tabular}{|l|l|l|l|l|}
\hline & Frequency & Percent & $\begin{array}{l}\text { Valid } \\
\text { Percent }\end{array}$ & $\begin{array}{l}\text { Cumulative } \\
\text { Percent }\end{array}$ \\
\hline $\begin{array}{l}\text { Sangat } \\
\text { Tidak Baik }\end{array}$ & 1 & 2.9 & 3.0 & 3.0 \\
\hline Tidak Baik & 8 & 23.5 & 24.2 & 27.3 \\
\hline Baik & 17 & 50.0 & 51.5 & 78.8 \\
\hline $\begin{array}{l}\text { Sangat } \\
\text { Baik }\end{array}$ & 7 & 20.6 & 21.2 & 100.0 \\
\hline
\end{tabular}

Tabel 4 menjelaskan bahwa game edukasi ini user friendly dinyatakan baik. Hal ini ditunjukkan dengan presentase audience sebesar $51.5 \%$.

\section{TABEL 5. HASIL PENGUJIAN PERTANYAAN 5}

\begin{tabular}{|l|l|l|l|l|}
\hline & Frequency & Percent & $\begin{array}{c}\text { Valid } \\
\text { Percent }\end{array}$ & $\begin{array}{c}\text { Cumulative } \\
\text { Percent }\end{array}$ \\
\hline Sangat Tidak Baik & 2 & 5.9 & 6.1 & 6.1 \\
\hline Tidak Baik & 14 & 41.2 & 42.4 & 48.5 \\
\hline Baik & 17 & 50.0 & 51.5 & 100.0 \\
\hline Total & 33 & 97.1 & 100.0 & \\
\hline
\end{tabular}

Tabel 5 menjelaskan bahwa fungsi tombol dengan tujuan menu yang diinginkan dinyatakan baik. Hal ini ditunjukkan dengan presentase audience sebesar $51.5 \%$.

TABEL 6. HASIL PENGUJIAN PERTANYAAN 6

\begin{tabular}{|l|l|l|l|l|}
\hline & Frequency & Percent & $\begin{array}{l}\text { Valid } \\
\text { Percent }\end{array}$ & $\begin{array}{l}\text { Cumulative } \\
\text { Percent }\end{array}$ \\
\hline $\begin{array}{l}\text { Sangat Tidak } \\
\text { Baik }\end{array}$ & 6 & 17.6 & 18.2 & 18.2 \\
\hline Tidak Baik & 20 & 58.8 & 60.6 & 78.8 \\
\hline Baik & 7 & 20.6 & 21.2 & 100.0 \\
\hline Total & 33 & 97.1 & 100.0 & \\
\hline
\end{tabular}

Table 6 menjelaskan bahwa kesesuaian tampilan animasi dinyatakan tidak baik. Hal ini ditunjukkan dengan presentase audience sebesar $60.6 \%$.

\begin{tabular}{|l|l|l|l|l|}
\multicolumn{2}{c}{ Tabel 7. Hasil pengujian pertanyaan 7 } \\
& Frequency & Percent & $\begin{array}{l}\text { Valid } \\
\text { Percent }\end{array}$ & $\begin{array}{l}\text { Cumulative } \\
\text { Percent }\end{array}$ \\
\hline Tidak Baik & 6 & 17.6 & 18.2 & 18.2 \\
\hline Baik & 19 & 55.9 & 57.6 & 75.8 \\
\hline Sangat Baik & 8 & 23.5 & 24.2 & 100.0 \\
\hline Total & 33 & 97.1 & 100.0 & \\
\hline
\end{tabular}

Table 7 menjelaskan bahwa Kesesuaian ilustrasi musik dalam

\begin{tabular}{|l|l|l|l|l|}
\hline & $\begin{array}{l}\text { Frequenc } \\
\mathbf{y}\end{array}$ & Percent & $\begin{array}{l}\text { Valid } \\
\text { Percent }\end{array}$ & $\begin{array}{l}\text { Cumulative } \\
\text { Percent }\end{array}$ \\
\hline $\begin{array}{l}\text { Sangat Tidak } \\
\text { Baik }\end{array}$ & 6 & 17.6 & 18.2 & 18.2 \\
\hline Tidak Baik & 19 & 55.9 & 57.6 & 75.8 \\
\hline Baik & 8 & 23.5 & 24.2 & 100.0 \\
\hline Total & 33 & 97.1 & 100.0 & \\
\hline
\end{tabular}
mendukung education game untuk belajar berhitung dinyatakan baik. Hal ini ditunjukkan dengan presentase audience sebesar $57.6 \%$.

TABEL 8. HASIL PENGUJIAN PERTANYAAN 8

\begin{tabular}{|l|l|l|l|l|}
\hline & Frequency & Percent & $\begin{array}{l}\text { Valid } \\
\text { Percent }\end{array}$ & $\begin{array}{l}\text { Cumulative } \\
\text { Percent }\end{array}$ \\
\hline $\begin{array}{l}\text { Sangat Tidak } \\
\text { Baik }\end{array}$ & 5 & 14.7 & 15.2 & 15.2 \\
\hline Tidak Baik & 17 & 50.0 & 51.5 & 66.7 \\
\hline Baik & 9 & 26.5 & 27.3 & 93.9 \\
\hline Sangat Baik & 2 & 5.9 & 6.1 & 100.0 \\
\hline
\end{tabular}


\begin{tabular}{|l|l|l|l|l|}
\hline Total & 33 & 97.1 & 100.0 & \\
\hline
\end{tabular}

Tabel 8 menjelaskan bahwa ketepatan pemilihan warna tulisan dinyatakan tidak baik. Hal ini ditunjukkan dengan presentase audience sebesar $51.5 \%$.

\begin{tabular}{|l|l|l|l|l|}
\multicolumn{2}{|c|}{ TABEL 9. HASIL PENGUJAAN PERTANYAAN 9 } \\
\hline & Frequency & Percent & $\begin{array}{l}\text { Valid } \\
\text { Percent }\end{array}$ & $\begin{array}{l}\text { Cumulative } \\
\text { Percent }\end{array}$ \\
\hline Sangat Tidak Baik & 8 & 23.5 & 24.2 & 24.2 \\
\hline Tidak Baik & 21 & 11.8 & 12.1 & 12.1 \\
\hline Baik & 4 & 61.8 & 63.6 & 100.0 \\
\hline Total & 33 & 97.1 & 100.0 & \\
\hline
\end{tabular}

Tabel 9 menjelaskan bahwa kesesuaian ukuran tombol dinyatakan baik. Hal ini ditunjukkan dengan presentase audience sebesar $63.6 \%$.

TABEL 10. HASIL PERTANYAAN NOMOE 10

\begin{tabular}{|l|l|l|l|l|}
\hline & Frequency & Percent & $\begin{array}{l}\text { Valid } \\
\text { Percent }\end{array}$ & $\begin{array}{l}\text { Cumulative } \\
\text { Percent }\end{array}$ \\
\hline $\begin{array}{l}\text { Sangat Tidak } \\
\text { Baik }\end{array}$ & 2 & 5.9 & 6.1 & 6.1 \\
\hline Tidak Baik & 10 & 29.4 & 30.3 & 36.4 \\
\hline Baik & 19 & 55.9 & 57.6 & 93.9 \\
\hline Sangat Baik & 2 & 5.9 & 6.1 & 100.0 \\
\hline Total & 33 & 97.1 & 100.0 & \\
\hline
\end{tabular}

Tabel 10 menjelaskan bahwa kesesuaian bentuk tombol dinyatakan baik. Hal ini ditunjukkan dengan presentase audience sebesar $57.6 \%$.

TABEL 11. HASIL ORAH DATA PERTANYAAN 10

\begin{tabular}{|l|l|l|l|l|}
\hline & $\begin{array}{l}\text { Frequenc } \\
\mathbf{y}\end{array}$ & Percent & $\begin{array}{l}\text { Valid } \\
\text { Percent }\end{array}$ & $\begin{array}{l}\text { Cumulative } \\
\text { Percent }\end{array}$ \\
\hline Sangat Tidak Baik & 2 & 5.9 & 6.1 & 6.1 \\
\hline Tidak Baik & 8 & 23.5 & 24.2 & 30.3 \\
\hline Baik & 15 & 44.1 & 45.5 & 75.8 \\
\hline Sangat Baik & 8 & 23.5 & 24.2 & 100.0 \\
\hline Total & 33 & 97.1 & 100.0 & \\
\hline
\end{tabular}

Tabel 11 menjelaskan bahwa kenyamanan menggunakan aplikasi secara keseluruhan dinyatakan baik. Hal ini ditunjukkan dengan presentase audience sebesar $45.5 \%$.

Sehingga secara keseluruhan aplikasi game edukasi ini dinyatakan baik dan layak digunakan untuk anak usia dini.

\section{KESIMPULAN}

Adapun kesimpulan pada penelitian ini adalah game berbasis mobile ini baik dan bias digunakan oleh anak usia dini selama musim pandemic COVID-19. Hal ini terlihat dari beberapa hasil uji dari 10 pertanyaan yang rata-rata menjawab baik dan sangat baik yaitu sekitar $70 \%$. Kedepannya game ini akan dikembangkan lagi dengan karakter dan aset yang lebih baik dan dengan jalan cerita yang lebih menantang.

\section{REFERENCES}

[1] “34e9520bf8bef69295af70868d73448db39d98f9 @ dailysocial.id.” [Online]. Available: https://dailysocial.id/post/melirik-potensibesar-industri-gaming-di-indonesia/.

[2] E. Haryanto and H. Askad, "Rancang Bangun Game Adventure Burung Enggang Berbasis Android Menggunakan Scirra Construct 2," pp. 1771-1782, 2013.

[3] M. R. Rahadi, K. I. Satoto, and I. P. Windasari, "Perancangan Game Math Adventure Sebagai Media Pembelajaran Matematika Berbasis Android," J. Teknol. dan Sist. Komput., vol. 4, no. 1, p. 44, 2016 doi: 10.14710/jtsiskom.4.1.2016.44-49.

[4] R. Bahana et al., "Performance test for prototype game for children with adhd," J. Phys. Conf. Ser., vol. 978, no. 1, 2018, doi: 10.1088/1742-6596/978/1/012004.

[5] "game-engine-construct-2@www.kompasiana.com." [Online]. Available:

https://www.kompasiana.com/mandowen10/5cff5ef53d68d51e7355 bce $2 /$ game-engine-construct-2.

[6] F. N. Khasanah, S. Murdowo, T. Informatika, U. Bina, P. Beta, and P. N. Fungsional, "Pengujian Beta Pada Aplikasi Game Edukasi," Infokam, vol. 15, no. 2, pp. 83-89, 2019. 